\title{
Prevalence and clinical significance of liver function abnormalities in patients with acute heart failure
}

\author{
Klaudia Vyskocilova ${ }^{a}$, Lenka Spinarova ${ }^{a}$, Jindrich Spinar ${ }^{b}$, Tereza Mikusovaa, Jiri Vitovec ${ }^{a}$, Josef Malekc, Filip Malek ${ }^{d}$, \\ Ales Linharte, Marian Fedorco ${ }^{f}$, Petr Widimsky ${ }^{9}$, Cestmir Cihalikk', Jiri Parenicab ${ }^{b}$, Simona Littnerova', Jiri Jarkovsky'
}

\begin{abstract}
Aims. Liver pathology caused by cardiac dysfunction is relatively well recognized, however, its clinical importance has not been fully evaluated. The aim of this study was to assess the prevalence of liver function tests (LFTs) abnormalities and to identify associated factors mediating hepatic impairment in patients with acute heart failure (AHF).

Methods. The AHEAD (Acute Heart Failure Database) registry is a database conducted in 9 university hospitals and 5 regional health care facilities in the Czech Republic. From December 2004 to October 2012, the data of 8818 patients were included. The inclusion criteria for the database followed the European guidelines for AHF. Serum activities of all LFTs and total bilirubin were available in 1473 patients at the baseline.

Results. In patients with AHF, abnormal LFTs were seen in $76 \%$ patients (total bilirubin in 34\%, $\gamma$-glutamyltransferase in 44\%, alkaline phosphatase in 20\%, aspartate aminotransferase in 42\%, alanine aminotransferase in 35\%). Patients with cardiogenic shock were more likely to have LFTs abnormalities compared to mild AHF and pulmonary oedema. LFTs abnormalities were strongly associated with AHF severity (left ventricular ejection fraction and NYHA functional class) and clinical manifestation. While hepatocellular LFTs pattern predominated in left sided forward AHF, cholestatic profile occurred mainly in bilateral and right sided AHF. Additionally, patients with moderate to severe tricuspid regurgitation had significantly higher prevalence of abnormalities in cholestatic LFTs.

Conclusions. Defining the LFTs profile typical for AHF plays an important role in management of AHF patients, since it may avoid redundant hepatic investigations and diagnostic misinterpretations.
\end{abstract}

Key words: heart failure, liver function tests, bilirubin, congestive hepatopathy, ischemic hepatitis

Received: September 11, 2013; Accepted: March 4, 2014; Available online: March 13, 2014 http://dx.doi.org/10.5507/bp.2014.014

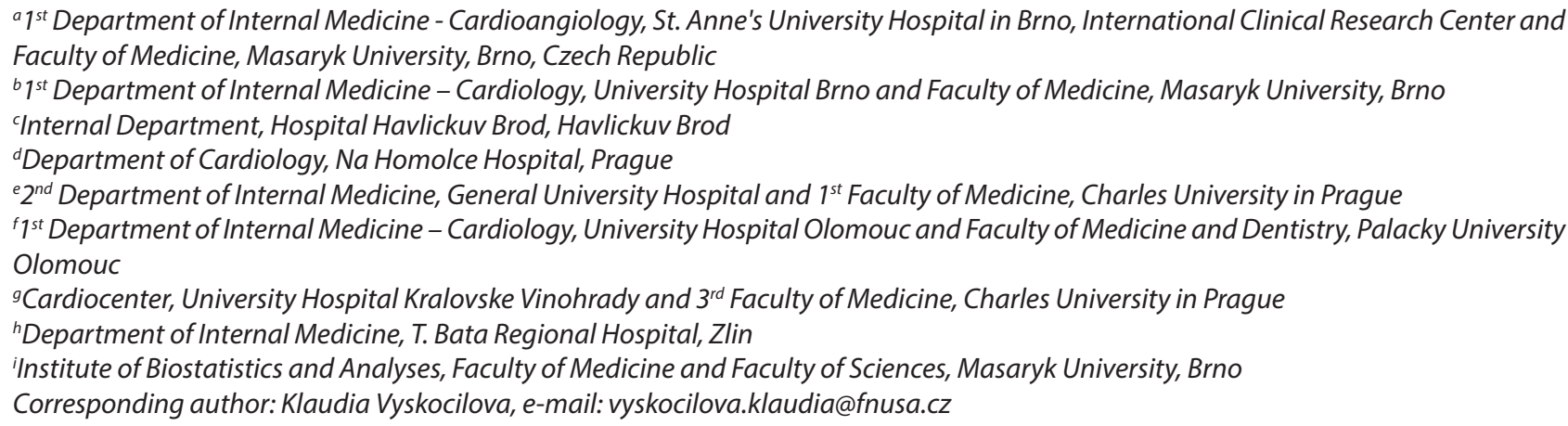

\section{INTRODUCTION}

Cardiac failure has a negative impact on the function of all parenchymatous organs, based both on the low organ perfusion in the left-sided forward failure and on the venous congestion in the right-sided backward failure ${ }^{1}$. Most of the studies have been focused on cardiorenal syndromes, however, the impact of cardiac failure on liver function is also considerable $e^{2,3}$.

Common histopatological findings of hepatic impairment caused by heart failure embrace inflammatory changes, sinusoidal dilatation, necrosis and fibrosis - all these features occur both in centrilobular and periportal location. While stage of fibrosis has been described mostly in chronic right-sided heart failure, centrilobular or periportal necrosis have mainly been seen in acute heart failure (AHF) patients (Fig. 1) (ref. $\left.{ }^{4,5}\right)$.

Current studies dealing with cardiac hepatopathy focus predominantly on the liver enzyme changes by analysing clinical and prognostic relevance of liver function tests (LFTs) abnormalities in patients with chronic heart failure. Strikingly, there are only few works investigating the liver involvement in AHF (Table 1) (ref. ${ }^{6-14}$ ).

The aim of this study was to evaluate the prevalence of LFTs abnormalities and to identify associated cardiac and noncardiac factors mediating hepatic impairment in $\mathrm{AHF}$ - new onset (de novo) heart failure as well as acute exacerbation of chronic. 


\section{MATERIALS AND METHODS}

The AHEAD (Acute Heart Failure Database) registry is a Czech multi-centric database conducted in 9 university hospitals with a 24-h Catheterisation Laboratory service and 5 regional health care facilities. From December 2006 to October 2012, the data of 8818 patients with AHF were collected into the database prospectively. The inclusion criteria followed current European guidelines for AHF and patients were systematically classified according to type, clinical manifestation and aetiology of AHF (ref. ${ }^{15-17}$ ). The decision on inclusion in the registry and filling in the database was performed by experienced cardiologists through the Internet website http://www. ahead.registry.cz. There was no exclusion criterion and patients were enrolled only once during the study period. Written informed consent was obtained from all subjects and local ethics committees of involved centres approved the database protocol.

Serum activities of all LFTs - $\gamma$-glutamyltransferase (GGT), alkaline phosphatase (ALP), aspartate aminotransferase (AST), alanine aminotransferase (ALT) - and total bilirubin (T-BIL) were available in 1473 patients (592 women) at the baseline. Laboratory samples were collected on admission or on the $2^{\text {nd }}$ day of hospitalisation after overnight fasting. Abnormal levels of the laboratory values were set above the upper limit of reference range that was specific for each involved centre laboratory.

\section{Statistical Analysis}

Data analysis was performed by the Institute of Biostatistics and Analyses of Masaryk University (Brno, Czech Republic) using the Statistical Package for Social Sciences (Release 19.0.1, IBM Corporation 2010). Standard descriptive statistics was applied in the analysis: absolute and relative frequencies for categorical variables and median supplemented by $5^{\text {th }}$ and $95^{\text {th }}$ percentile for continuous variables. Statistical significance of differences between pairs of groups of patients was computed using maximum likelihood chi-square test for categorical variables, Mann-Whitney test for continuous variables. Logistic regression was used to estimate of relationships between liver function tests and heart failure-related variables (univariate and multivariate). The level of statistical significance was set at $\alpha=0.05$.

\section{RESULTS}

\section{Baseline characteristics}

Of 1,473 patients with available LFTs serum levels, 724 (49\%) had de novo (newly diagnosed) heart failure and $359(24 \%)$ had acute coronary syndrome on admission. Mean age of the patients was 74 years and mean left ventricular ejection fraction was $35 \%$.

Table 2 shows baseline clinical characteristics including medical history and medication on admission of patient cohort according to types of AHF - divided into AHF with mild signs, pulmonary oedema (associated with severe respiratory distress, rales over the lungs and 


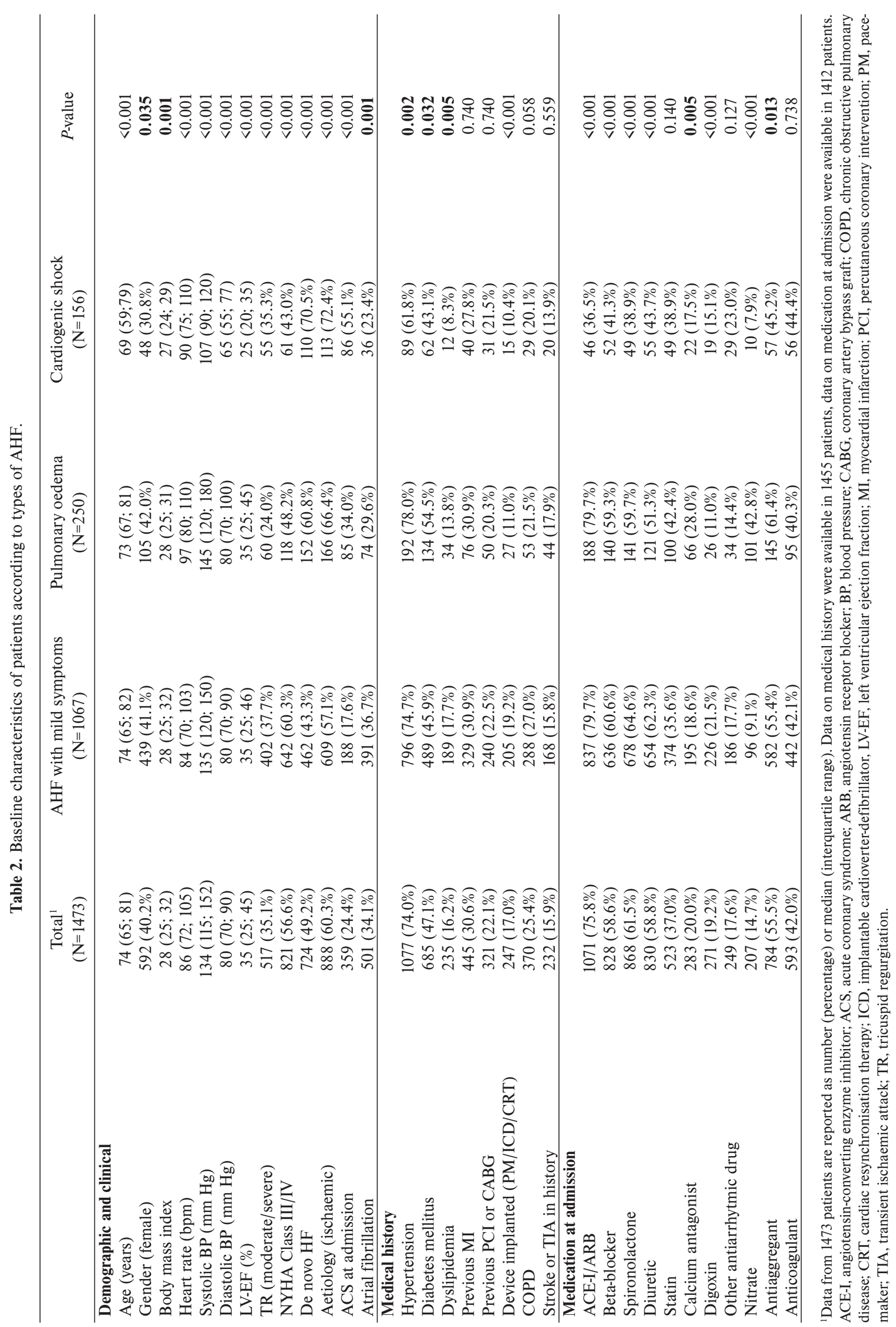


Table 3. Percentages of abnormal LFTs according to types of AHF.

\begin{tabular}{lccccr}
\hline & $\begin{array}{c}\text { Total } \\
(\mathrm{N}=1473)\end{array}$ & $\begin{array}{c}\text { AHF with mild } \\
\text { symptoms }(\mathrm{N}=1067)\end{array}$ & $\begin{array}{c}\text { Pulmonary oedema } \\
(\mathrm{N}=250)\end{array}$ & $\begin{array}{c}\text { Cardiogenic shock } \\
(\mathrm{N}=156)\end{array}$ & $P$ \\
\hline T-BIL $(\mu \mathrm{mol} / \mathrm{L})$ & $498(33.8 \%)$ & $377(35.3 \%)$ & $59(23.6 \%)$ & $62(39.7 \%)$ & $<0.001$ \\
GGT $(\mathrm{U} / \mathrm{L})$ & $653(44.3 \%)$ & $480(45.0 \%)$ & $97(38.8 \%)$ & $76(48.7 \%)$ & 0.104 \\
ALP $(\mathrm{U} / \mathrm{L})$ & $301(20.4 \%)$ & $219(20.5 \%)$ & $53(21.2 \%)$ & $29(18.6 \%)$ & 0.807 \\
AST $(\mathrm{U} / \mathrm{L})$ & $611(41.5 \%)$ & $363(34.0 \%)$ & $124(49.6 \%)$ & $124(79.5 \%)$ & $<0.001$ \\
ALT $(\mathrm{U} / \mathrm{L})$ & $508(34.5 \%)$ & $320(30.0 \%)$ & $82(32.8 \%)$ & $106(67.9 \%)$ & $<0.001$ \\
\hline
\end{tabular}

ALP, alkaline phosphatase; ALT, alanine aminotransferase; AST, aspartate aminotransferase; GGT, $\gamma$-glutamyltransferase; T-BIL, total bilirubin.

Table 4. Distribution of LFTs elevations according to presence of ACS.

\begin{tabular}{lcccc}
\hline & $\begin{array}{c}\text { Total }^{1} \\
(\mathrm{~N}=1473)\end{array}$ & $\begin{array}{c}\text { AHF with ACS } \\
(\mathrm{N}=359)\end{array}$ & $\begin{array}{c}\text { AHF without ACS } \\
(\mathrm{N}=1114)\end{array}$ & $P$ \\
\hline T-BIL (xULN) & $0.8(0.3 ; 2.2)$ & $0.7(0.3 ; 1.7)$ & $0.8(0.3 ; 2.3)$ & $<0.001$ \\
GGT (xULN) & $0.9(0.2 ; 5.0)$ & $0.7(0.2 ; 3.1)$ & $1.0(0.2 ; 5.2)$ & $<0.001$ \\
ALP (xULN) & $0.7(0.4 ; 1.7)$ & $0.6(0.3 ; 1.3)$ & $0.7(0.4 ; 1.8)$ & $<0.001$ \\
AST (xULN) & $0.9(0.4 ; 13.0)$ & $2.1(0.4 ; 24.0)$ & $0.7(0.4 ; 5.1)$ & $<0.001$ \\
ALT (xULN) & $0.7(0.3 ; 5.5)$ & $1.1(0.3 ; 7.0)$ & $0.7(0.3 ; 5.0)$ & $<0.001$ \\
\hline
\end{tabular}

${ }^{1}$ Data are reported as median $\left(5^{\text {th }} ; 95^{\text {th }}\right.$ percentil $)$.

ACS, acute coronary syndrome; ALP, alkaline phosphatase; ALT, alanine aminotransferase; AST, aspartate aminotransferase; GGT, $\gamma$-glutamyltransferase; T-BIL, total bilirubin; ULN, upper limit of normal.

oxygen hyposaturation prior treatment) and cardiogenic shock (defined as tissue hypoperfusion despite adequate intravascular volume induced by cardiac failure)( ref. $\left.^{15}\right)$. Patients with cardiogenic shock were significantly younger and more likely to have ischemic aetiology of AHF (both $P<0.001)$. They were in significantly better NYHA functional class $(P<0.001)$. that can be explained by higher prevalence of de novo onset of AHF and acute coronary syndromes in the shock group compared to pulmonary oedema and group with mild AHF symptoms (both $P<0.001)$.

\section{Prevalence of LFTs abnormalities in AHF}

In patients with AHF, abnormal LFTs were seen in $76 \%$ patients (T-BIL in 34\%, GGT in $44 \%$, ALP in $20 \%$, AST in $42 \%$, ALT in 35\%). Percentage of LFT abnormalities differed according to type of AHF. Patients with cardiogenic shock were more likely to have LFTs abnormalities $(P<0.001$ for T-BIL, AST, ALT, $P=N S$ for GGT, ALP) compared to AHF with mild symptoms and pulmonary oedema (Table 3 ).

\section{Clinical correlations of abnormal LFTs in AHF}

Concerning the distribution of LFTs elevations, the highest levels were seen in patients with acute coronary syndromes that had significantly higher transaminases (AST and ALT), while AHF patients without acute coronary syndromes had significantly higher cholestatic enzymes (T-BIL, GGT and ALP) - all $P<0.001$ (Table 4).

LFTs abnormalities were strongly associated with AHF severity and clinical manifestation. While bilateral and right sided AHF were mainly presented mainly by

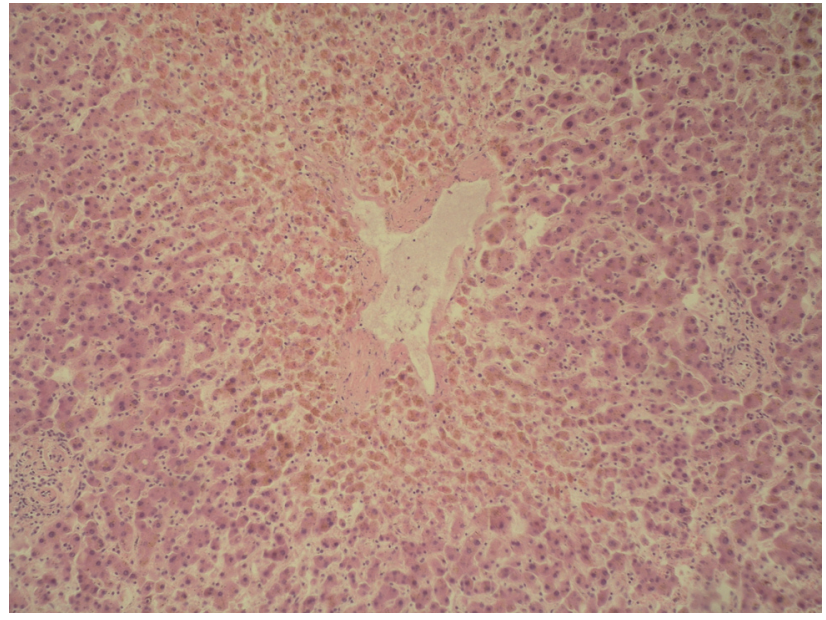

Fig. 1. Central necrosis in AHF (liver autopsy). Original magnification $\mathrm{x} 400$, hematoxylin-eosin stain (Courtesy of Dr. Lenz, St. Anne's Faculty Hospital, Brno, Czech Republic).

cholestatic LFT profile, for left sided forward AHF hepatocellular pattern (elevation of transaminases) was typical (Fig. 2).

Fig. 3 shows multivariate analysis of factors predicting abnormal LFTs. As expected, patients with newly diagnosed acute coronary syndromes on admission and also hypotensive patients (with systolic blood pressure less than $100 \mathrm{mmHg}$ ) had significantly higher prevalence of abnormal AST and ALT. Patients with left ventricular ejection fraction less than 30 had significantly greater likelihood to have abnormal T-BIL, GGT and AST. In 

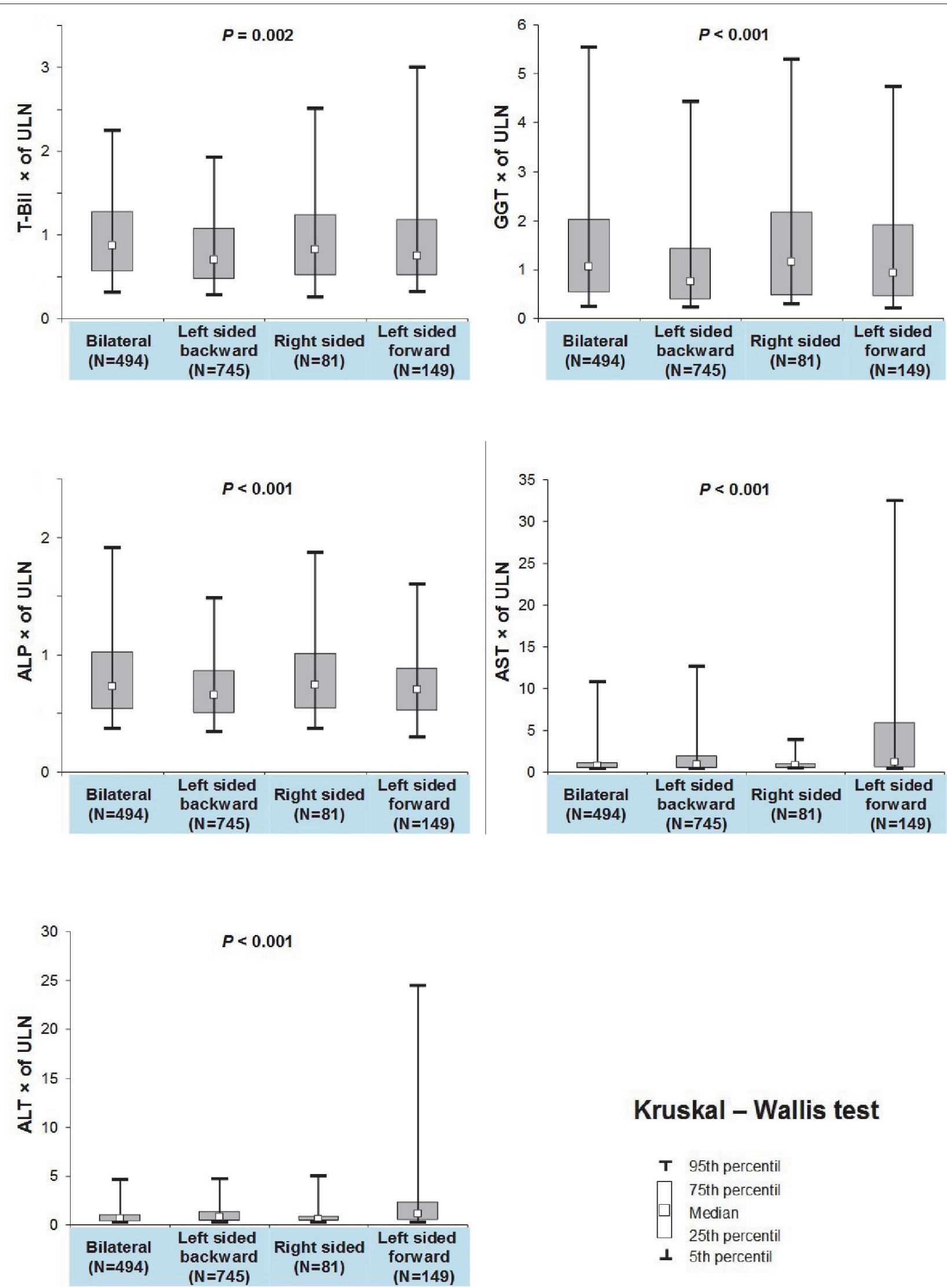

\section{Kruskal - Wallis test}

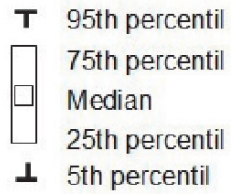

Fig. 2. Distribution of LFTs elevations according to clinical manifestation of AHF. 


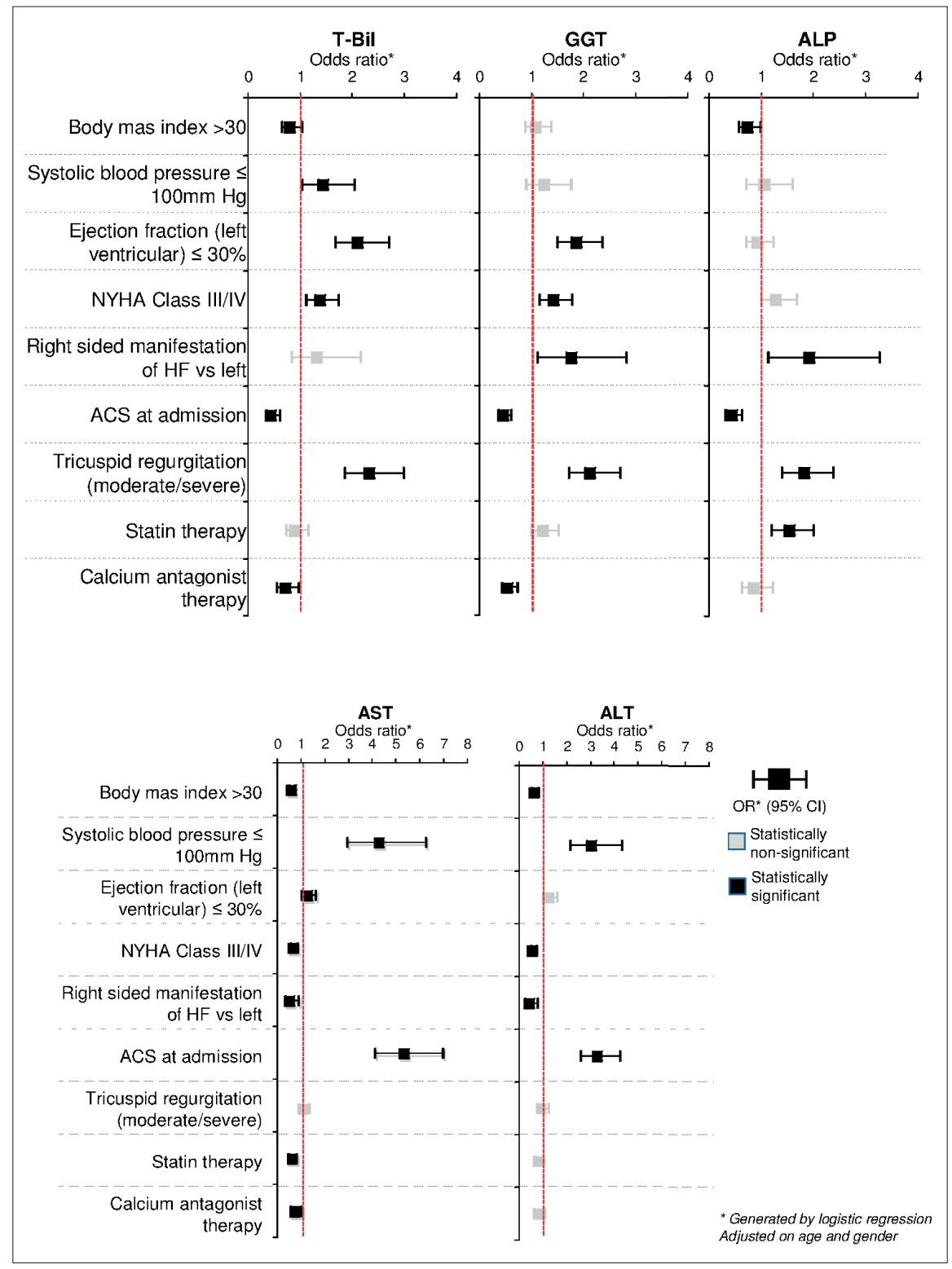

Fig. 3. Multivariate analysis of factors predicting abnormal LFTs.

addition, patients with moderate to severe tricuspid regurgitation had significantly higher prevalence of abnormalities in cholestatic LFTs (T-BIL, GGT, ALP). Patients with worse NYHA class had significantly higher abnormalities among all LFTs except ALP. Of noncardiac factors, surprisingly, higher body mass index predicts better liver condition concerning all LFTs in AHF. While potential harmful effect of statin therapy is not convincing from our results, there may be a protective effect of calcium antagonist therapy (statistically significant for T-BIL, GGT, AST).

\section{DISCUSSION}

In our study, prevalence of LFTs abnormalities was relatively high, however, it did not differ markedly from other similar studies with AHF patients when taking into account some important patients characteristics - see
Table 1 (ref $^{6-14}$ ). Concerning T-BIL, according Shinigava et al the prevalence of abnormal serum levels was much higher (64\%) compared to work of Lau et al (19\%) and this study (34\%). Nevertheless, Shinigava did not include de novo AHF and that can explain such high prevalence of T-BIL abnormalities, associated mostly with chronic (predominantly right-sided) cardiac failure. Regarding abnormal ALP and GGT, results were almost identical compared to other relevant studies (for ALP - 21\% and $22 \%$ vs $20 \%$ found in our study, for GGT - $41 \%$ vs $44 \%$ found in our study). Of transaminases, prevalence of abnormal levels of AST and ALT in our study was higher than previously reported $(42 \%$ and $35 \%$, respectively compared to $33 \%$ and $25 \%$ in study of Nikolau et al and $4 \%$ and $7 \%$ in study of Lau et al, respectively) (ref. ${ }^{7,11,14}$ ). Lower prevalence of abnormal transaminases in Lau's work was caused by exclusion of acute myocardial infarction patients from the study. In our study, percentage of acute coronary syndromes was high ( $24 \%$ - in comparison 
with $15 \%$ reported in Nikolau's work) and that explains high prevalence of transaminase abnormalities in our patient cohort ${ }^{7,14}$.

Similarly as described in previous studies, we have also proven that there are certain clinical features associated with specific LFTs profile - whereas elevation of cholestatic enzymes occurs mainly in right-sided heart failure (based on the systemic congestion), elevation of transaminases is mainly connected with the clinical signs of hypoperfusion (systemic hypotension) (ref., ${ }^{7,14}$ ). Concerning the right-sided heart failure, the role of the tricuspid regurgitation in elevation of cholestatic LFTs is convincing from our study. Furthermore, our data suggest that LFTs abnormalities are strongly associated with AHF severity - lower left ventricular ejection fraction predicts higher prevalence of all LFTs abnormalities, moreover, worse NYHA functional class (grade III and IV) is associated with cholestatic LFTs pattern - see Fig. 3. Considerable is better clinical stage (NYHA functional class grade I and II) of patients with elevated transminases - we are convinced that this patient group embraces de novo AHF and also acute coronary syndromes with no or lower previous evidence of heart failure symptoms.

By evaluation of noncardiac features, role of the body mass index in predicting abnormal LFTs is questionable - patients with body mass index more than 30 had less frequent all LFTs abnormalities in our study. We assume that patients with cardiac cachexia and so lower body mass index were in worse clinical stage of AHF that contributed to higher occurrence of LFTs abnormalities.

We also investigated the potential harmful effect of statin therapy in AHF patients. Statins have wide spectrum of liver side effects, the most common is an asymptomatic elevation of transaminases without histopatological changes of the liver parenchyma. This phenomenon occurs mostly during the first three months after starting the therapy and is described as "transaminitis" (ref. ${ }^{18}$ ). Our data correspond with the prevailing opinion in current literature that elevation of transaminases in patients taking statins is not much clinically relevant ${ }^{19-21}$. However, rare case reports when statin therapy led to autoimmune hepatitis or liver cirrhosis must be taken into consideration in the AHF patients management ${ }^{22-23}$.

The surprising potential protective effect of calcium antagonist therapy (statistically significant for T-BIL, GGT, AST in our study) may be explained by less severe ventricular dysfunction in patients using calcium channel antagonists. Still, there are some results from animal studies indicating that calcium antagonists can reduce the increase of LFTs and development of liver fibrosis ${ }^{24-25}$.

\section{CONCLUSIONS}

In patients with AHF, abnormal LFTs were seen in $76 \%$ patients (T-BIL in $34 \%$, GGT in $44 \%$, ALP in $20 \%$, AST in $42 \%$, ALT in 35\%). Percentage of LFTs abnormalities varied according to type of AHF. Patients with cardiogenic shock were more likely to have LFTs abnor- malities compared to ADHF with mild symptoms and pulmonary oedema. Concerning the distribution of LFTs elevations, the highest levels were seen in patients with acute coronary syndromes that had significantly higher transaminases, particularly AST, while AHF patients without acute coronary syndromes presented more likely with cholestatic LFTs profile.

LFTs abnormalities were strongly associated with AHF severity (left ventricular ejection fraction and NYHA functional class) and clinical manifestation. Left sided forward AHF was presented predominantly by hepatocelullar pattern whereas cholestatic LFTs profile occurred mainly in bilateral and right sided AHF. Additionally, patients with moderate to severe tricuspid regurgitation had significantly higher prevalence of abnormalities in cholestatic LFTs.

In summary, defining the LFTs profile typical for AHF plays an important role in management of AHF patients, since it may avoid redundant hepatic investigations and diagnostic misinterpretations. Furthermore, early recognition of hepatic impairment may warrant more intensive treatment of AHF and therapy optimisation.

\section{Limitations}

We do acknowledge limitations of this study. The study had an observational character - patient inclusion depended on the personal decision of the physician and therefore data filled in the database may be biased. Invasive haemodynamic data and information on liver pathology such as hepatitis serology or immunology tests or liver imaging were not available.

Concerning the panel of LFTs, albumin and prothrombin time were not recorded in the database. We did not investigate LFTs and T-BIL changes during hospitalisation. Patients with alcohol consumption were not excluded and potential hepatotoxic medications such as amiodarone or antibiotics were not followed. Moreover, echocardiographic measurements were performed by different cardiologists that may lead to data inconsistencies.

\section{ABBREVIATIONS}

ACE-I, Angiotensin-converting enzyme inhibitor; ACS, Acute coronary syndrome; AHF, Acute heart failure; ALB, Albumin; ALP, Alkaline phosphatase; ALT, Alanine aminotransferase; ARB, Angiotensin receptor blocker; AST, Aspartate aminotransferase; BP, Blood pressure; CABG, Coronary artery bypass graft; COPD, Chronic obstructive pulmonary disease; CRT, Cardiac resynchronisation therapy; GGT, $\gamma$-glutamyltransferase; ICD, Implantable cardioverter-defibrillator; LD, Lactate dehydrogenase; LFTs, Liver function tests; LV-EF, Left ventricular ejection fraction; MI, Myocardial infarction; PCI, Percutaneous coronary intervention; PM, Pacemaker; TIA, Transient ischaemic attack; T-BIL, Total bilirubin; TR, Tricuspid regurgitation; ULN, Upper limit of normal. 


\section{ACKNOWLEDGEMENT}

We thank the study investigators for their contribution to the study.

Participating centres and investigators: University Hospital Brno, Brno: Roman Miklik, Marian Felsoci, Kateřina Horakova, Ondrej Ludka; General University Hospital, Prague: Jan Belohlávek; University Hospital Kralovske Vinohrady, Prague: Filip Rohac, Richard Fojt; University Hospital, Olomouc: Jan Vaclavik, David Vindis; T. Bata Regional Hospital, Zlin: Zdenek Coufal, Petr Hrdy, Stanislava Penasova, Miroslav Bambuch; Hospital Havlickuv Brod, Havlickuv Brod: Ladislava Malkova; Hospital in Frydek-Mistek, Frydek-Mistek: Pohludova L., Zeman K.

The project was supported by grant IGA 9880-3 of the Czech Ministry of Health, grant MSM0021622402 of the Czech Ministry of Education, Youth and Sports and by European Regional Development Fund - Project FNUSA-ICRC (No.CZ.1.05/1.1.00/02.0123).

Author contributions: KV: manuscript writing and data collection, LS: data interpretation and manuscript writing, JS and JP: study design, TM, JV, JM, FM, AL, MF, PW, CC: data collection; SL and JJ: data analysis, statistical analysis, figures.

Conflicts of interests statement: None declared.

\section{REFERENCES}

1. Samsky MD, Patel CB, DeWald TA, Smith AD, Felker GM, Rogers JG, Hernandez AF. Cardiohepatic interactions in heart failure: An overview and clinical implications. J Am Coll Cardiol 2013;61(24):2397405.

2. Mebazaa A. Congestion and cardiorenal syndromes. Contrib Nephrol 2010;165:140-4.

3. Mentz RJ, O'Conor CM. Cardiorenal syndrome clinical trial end points. Heart Fail Clin 2011;7(4):519-28.

4. Myers RP, Cerini R, Sayegh R, Moreau R, Degott C, Lebrec D, Lee SS. Cardiac hepatopathy: clinical, hemodynamic, and histologic characteristics and correlations. Hepatology 2003;37:393-400.

5. Killip T, Payne MA. High serum transaminase activity in heart disease. Circulatory failure and hepatic necrosis. Circulation 1960;21:646-60.

6. Allen LA, Felker GM, Pocock S, McMurray JJV, Pfeffer MA, Swedberg K, Wang D, Yusuf S, Michelson EL, Granger CB. Liver function abnormalities and outcome in patients with chronic heart failure: data from the Candesartan in heart failure: assessment of reduction in mortality and morbidity (CHARM) program. Eur J Heart Fail 2009;11:170-7.

7. Nikolau M, Parissis J, Yilmaz MB, Seronde MF, Kivikko M, Laribi S Paugam-Burtz C, Cai D, Pohjanjousi P, Laterre PF, Deye N, Poder P, Cohen-Solal A, Mebazaa A. Liver function abnormalities, clinical profile, and outcome in acute decompensated heart failure. Eur Heart J 2013;34:742-9.

8. Poelzl G, Ess M, Mussner-Seeber C, Pachinger O, Frick M, Ulmer H. Liver dysfunction in chronic heart failure: prevalence, characteristics and prognostic significance. Eur J Clin Invest 2012;42(2):153-63.

9. Batin P, Wickens M, McEntegart D, Fullwood L, Cowley AJ. The importance of abnormalities of liver function tests in predicting mortality in chronic heart failure. Eur Heart J 1995;16:1613-8.

10. Van Deursen VM, Damman K, Hillege HL, Van Beek AP, Van Veldhuisen DJ, Voors AA. Abnormal liver function in relation to hemodynamic profile in heart failure patients. J Card Fail 2010;16:84-90.
11. Shinagawa $H$, Inomata $T$, Koitabashi T, Nakano $H$, Takeuchi I, Naruke T, Ohsaka T, Nischii M, Takehana H, Izumi T. Prognostic significance of increased serum bilirubin levels coincident with cardiac decompensation in chronic heart failure. Circ J 2008;72:364-9.

12. Felder L, Mund A, Parker JG. Liver function tests in chronic congestive heart failure. Circulation 1950;2:286-97.

13. Kubo SH, Walter BA, John DH, Clark M, Cody RJ. Liver function abnormalities in chronic heart failure. Influence of systemic hemodynamics. Arch Intern Med 1987;147:1227-30.

14. Lau GT, Tan HC, Kritharides L. Type of liver dysfunction in heart failure nad its relation to the severity of tricuspid regurgitation. Am J Cardiol 2002;90:1405-9.

15. Nieminen MS, Böhm M, Cowie MR, Drexler H, Filippatos GS, Jondeau G, Hasin Y, Lopez-Sendon J, Mebazaa A, Metra M, Rhodes A, Swedberg K, Priori SG, Garcia MA, Blanc JJ, Budaj A, Cowie MR, Dean V, Deckers J, Burgos EF, Lekakis J, Lindahl B, Mazzotta G, Morais J, Oto A, Smiseth OA, Garcia MA, Dickstein K, Albuquerque A, Conthe P, Crespo-Leiro M, Ferrari R, Follath F, Gavazzi A, Janssens U, Komajda M, Morais J, Moreno R, Singer M, Singh S, Tendera M, Thygesen K. Executive summary of the guidelines on the diagnosis and treatment of acute heart failure: the Task Force on Acute Heart Failure of the European Society of Cardiology. Eur Heart J 2005;26(4):384-416.

16. Dickstein K, Cohen-Solal A, Filippatos G, McMurray JJ, Ponikowski P, Poole-Wilson PA, Strömberg A, van Veldhuisen DJ, Atar D, Hoes AW, Keren A, Mebazaa A, Nieminen M, Priori SG, Swedberg K. ESC guidelines for the diagnosis and treatment of acute and chronic heart failure 2008: the Task Force for the diagnosis and treatment of acute and chronic heart failure 2008 of the European Society of Cardiology. Developed in collaboration with the Heart Failure Association of the ESC (HFA) and endorsed by the European Society of Intensive Care Medicine (ESICM). Eur J Heart Fail 2008;10(10):93389.

17. McMurray JJ, Adamopoulos S, Anker SD, Auricchio A, Böhm M, Dickstein K, Falk V, Filippatos G, Fonseca C, Gomez-Sanchez MA, Jaarsma T, Køber L, Lip GY, Maggioni AP, Parkhomenko A, Pieske BM, Popescu BA, Rønnevik PK, Rutten FH, Schwitter J, Seferovic P, Stepinska J, Trindade PT, Voors AA, Zannad F, Zeiher A; ESC Committee for Practice Guidelines. ESC Guidelines for the diagnosis and treatment of acute and chronic heart failure 2012: The Task Force for the Diagnosis and Treatment of Acute and Chronic Heart Failure 2012 of the European Society of Cardiology. Developed in collaboration with the Heart Failure Association (HFA) of the ESC. Eur Heart J 2012;33(14):1787-847.

18. Dujovne CA. Side effects of statins: hepatitis versus "transaminitis" - myositis versus "CPKitis". The American Journal of Cardiology 2002;89:1411-3.

19. Pasternak RC, Smith SC Jr, Bairey-Merz CN, Grundy SM, Cleeman J, Lenfant C; American College of Cardiology; American Heart Association; National Heart, Lung and Blood Institute. ACC/AHA/ NHLBI Clinical Advisory on the Use and Safety of Statins. Circulation 2002;106(8):1024-8.

20. Calderon RM, Cubeddu LX, Goldberg RB, Schiff ER. Statins in the treatment of dyslipidemia in the presence of elevated liver aminotransferase levels: a therapeutic dilemma. Mayo Clin Proc. 2010;85(4):349-56.

21. Bays H. Statin safety: an overview and assessment on the data 2005. Am J Cardiol 2006;97[suppl]:6C-26C.

22. Alla V, Abraham J, Siddiqui J, Raina D, Wu GY, Chalasani NP, Bonkovsky $\mathrm{HL}$. Autoimmune hepatitis triggered by statins. J Clin Gastroenterol 2006;40(8):757-61.

23. Punthakee Z, Scully LJ, Guindi MM, Ooi TC. Liver fibrosis attributed to lipid lowering medications: two cases. J Intern Med 2001;250(3):24954.

24. Piratvisuth T, Dunne JB, Williams R, Tredger JM. Amlodipine improves hepatic hemodynamic and metabolic function in the isolated perfused rat liver after sequential cold and warm ischemia. Transplantation 1995;60:23-8.

25. Cutrin C, Menino J, Carballo C, Parafita MA, Perez-Becerra E, Barrio E. Nifedipine in rat liver cirrhosis. Vet Hum Toxicol 1994;36:14-6. 